\title{
A CASE OF BALANCED LETHAL FACTORS IN MAIZE
}

\author{
A. BIANCHI and A. MORANDI
}

Istituto di Genetico vegetale dell'Universitd Cottolico del S. Cuore, Piocenzo Istituto di Genetica dell'Universitd di Milano, Milano, Italy

Received 6.i.62

BALANCED lethals systems although well known in plants have received scarce attention from maize geneticists, even though they may be of use in several instances of genetical research in maize. A case has, however, been known since I 929 when Phipps found that plants of the constitution $T u V_{8} / t u v_{8}$ bred true, since the $T u T u$ combination, although viable, is practically sterile, and the $v_{8} v_{8}$ combination gives a lethal virescence. More recently Bianchi and Mangelsdorf (I955) reported briefly on another case, which has the great advantage of depending on factors producing lethality at the very beginning of zygotic life.

\section{MATERIAL AND METHODS}

As mentioned in the abstract (Bianchi and Mangelsdorf, 1955) the defective endosperm factors $d e^{t 1}$ and $d e^{t 2}$ detected in maize-teosinte derivatives are linked with $s u$ (sugary endosperm), on chromosome 4. They, like other $d e^{t}$ factors, may be fairly stable on some genetical background, including that which has been used in the present study. This background includes the markers $y$ (white endosperm), $w x$ (waxy endosperm) and $b m$ (brown midrib) to facilitate a quick and reliable detection of contamination, both in scoring the ears and in hand pollinating the individual plants in the field.

As shown in fig. I the distinction between normal and defective seeds is obvious. Kernels $d e^{t_{1}} d e^{t_{1}}$ are inviable usually because they lack embryos, although it cannot be excluded that their abnormal endosperm could lead to lethality even in cases where an embryo were present. The lethality of $d e^{t 2} d e^{t 2}$ seeds, on the contrary, is mainly due, in the present genetical background, to the general reduction of the different kernel parts (Bianchi, 1959). The repulsion phase stock was built originally by $\mathrm{Dr}$ P. C. Mangelsdorf (Harvard University) by intercrossing plants heterozygous for one or other of the two defective factors and selecting among the selfpollinated progeny ears segregating in both factors. It was then made available to the senior author of this paper for further study. The stock has been maintained by simple self-pollination of plants grown from normal seeds of ears segregating about 50 per cent. of defectives (fig. I).

Since, as it will be seen below, there is a considerable variability in the per cent. of defectives for reasons to be discussed, and few "physiological" defectives are always detectable on every normal ear (Mangelsdorf, 1926), the following criterion has been adopted in the few doubtful cases when classifying the different ears. Ears presenting less than 5 per cent. of defectives were considered to have come from normal plants $\left(D e^{t 1} D e^{t 2} / D e^{t 1} D e^{t_{2}}\right)$ : as will be shown below most of them actually gave less than I per cent. of defectives. The great majority of the ears, however, segregated either two or one defective types (the latter, of course, as a consequence of recombination, since the experimental material consisted of $\left.D e^{t 1} d e^{t 2} / d e^{t 1} D e^{t 2}\right)$. Ears with a significant number of defectives were provisionally classified as follows : those showing from 5 to 37.5 per cent. defectives as coming from plants heterozygous for one or other of the two defective factors $\left(D e^{t_{1}} D e^{t_{2}}\right)$ 
$d e^{t_{1}} D e^{t_{2}}$ or $\left.D e^{t_{1}} D e^{t_{1}} / D e^{t_{1}} d e^{t_{2}}\right)$ and those showing more than 37.5 per cent. defectives as coming from plants heterozygous for both defectives in repulsion phase $\left(D e^{t 1} d e^{t 2}\right)$ $\left.d e^{t 1} D e^{t 2}\right)$. The value of 37.5 per cent. was chosen as midway between 25 per cent., which is expected when one factor is segregating, and 50 per cent. which is characteristic of balanced lethals.

It soon became apparent, however, that both classes were heterogeneous, as was clearly indicated by $\chi^{2}$ tests. Various factors might be involved, among them the occurrence of the coupling phase genotype $\left(D e^{t_{1}} D e^{t_{2}} / d e^{t_{1}} d e^{t^{2}}\right)$ carrying both defectives and giving rise to ears with defectives significantly in excess of 25 per cent. but much lower than 50 per cent. depending, of course, on the frequency of recombination between the $d e^{t}$ factors). Ears showing proportions of defectives departing significantly from the average values of 25 and 50 per cent. were regarded as coming from such coupling double heterozygotes. Admittedly the criterion is somewhat subjective but it is not wholly artificial.

\section{STATISTICAL APPROACH}

An important feature of a balanced lethal system is the rate of recombination between the two factors concerned. Estimates of this can be obtained from our data in different ways. A weighted value is given by the method of maximum likelihood (Hogben, I946) which has been adapted to our kind of data, as follows.

Indicating $A$ for $D e^{t 1}, B$ for $D e^{t 2}$ and $p$ for the frequency of recombination, selfing $A b / a B$ will give:

\begin{tabular}{|c|c|c|c|c|c|}
\hline & & $A b=\frac{1}{2}(1-p)$ & $a b=\frac{1}{2} p$ & $A B=\frac{1}{2} p$ & $a B=\frac{1}{2}(1-p)$ \\
\hline$A b=\frac{1}{2}(1-p)$ & • & $\begin{array}{l}A A b b \dagger \\
\frac{1}{1}(1-p)^{2}\end{array}$ & $\begin{array}{c}A a b b \dagger \\
t p(1-p)\end{array}$ & $\begin{array}{c}A A B b \\
\downarrow p(1-p)\end{array}$ & $\begin{array}{c}A a B b \\
\frac{1}{4}(1-p)^{2}\end{array}$ \\
\hline$a b=\frac{1}{2} p$ & . & $\begin{array}{c}A a b b \dagger \\
\downarrow p(1-p)\end{array}$ & $\underset{t p^{2}}{a a b b \dagger}$ & $\begin{array}{c}A a B b \\
\pm p^{2}\end{array}$ & $\begin{array}{c}a a B b \dagger \\
\dot{q} p(1-p)\end{array}$ \\
\hline$A B=\frac{1}{2} p$ & & $\begin{array}{c}A A B b \\
\frac{1}{t} p(1-p)\end{array}$ & $\begin{array}{c}A a B b \\
1 p^{2}\end{array}$ & $\underset{+p^{2}}{A A B B}$ & $\begin{array}{c}A a B B \\
\downarrow p(1-p)\end{array}$ \\
\hline$a B=\frac{1}{2}(1-p)$ & & $\begin{array}{c}A a B b \\
\frac{1}{\ddagger}(1-p)^{2}\end{array}$ & $\begin{array}{c}a a B b \dagger \\
t p(1-p)\end{array}$ & $\begin{array}{c}A a B B \\
\downarrow p(1-p)\end{array}$ & $\begin{array}{c}a a B B \dagger \\
\frac{1}{d}(1-p)^{2}\end{array}$ \\
\hline
\end{tabular}

Taking into account the fact that the genotypic combinations marked $\dagger$ are lethal, we may tabulate our expected frequency from self-pollination of $A b / a B$ individuals as follows:

\begin{tabular}{|c|c|c|c|c|}
\hline Ears segregating & $\begin{array}{l}\text { Two defectives } \\
\text { in repulsion }\end{array}$ & $\begin{array}{c}\text { One } \\
\text { defective }\end{array}$ & $\begin{array}{l}\text { Two defectives } \\
\text { in coupling }\end{array}$ & $\begin{array}{c}\text { No } \\
\text { defectives }\end{array}$ \\
\hline Expected proportions & $\begin{array}{c}2 A a B b: \\
2 \cdot 1(1-p)^{2} \\
=\frac{1}{2}(1-p)^{2}\end{array}$ & $\begin{array}{l}2 A A B b, 2 A a B B \\
4.1 p(1-p) \\
\quad=p(1-p)\end{array}$ & $\begin{array}{l}2 A a B b: \\
2 \cdot \frac{1}{p^{2}}=\frac{1}{2} p^{2}\end{array}$ & $\begin{array}{c}A A B B: \\
\frac{1}{4} p^{2}\end{array}$ \\
\hline Observed. & $e$ & $f$ & $g$ & $h$ \\
\hline
\end{tabular}


Since the four classes in the table add up to $\frac{1}{2}\left(\mathrm{I}+\frac{1}{2} p^{2}\right)$, the expectations may be written as $\frac{(\mathrm{I}-p)^{2}}{\mathrm{I}+\frac{1}{2} p^{2}} ; \frac{2 p(\mathrm{I}-p)}{\mathrm{I}+\frac{1}{2} p^{2}} ; \frac{p^{2}}{\mathrm{I}+\frac{1}{2} p^{2}} ;$ and $\frac{\frac{1}{2} p^{2}}{\mathrm{I}+\frac{1}{2} p^{2}}$

The likelihood is then given by:

$$
\left[\frac{(\mathrm{I}-p)^{2}}{\mathrm{I}+\frac{1}{2} p^{2}}\right]^{e} \cdot\left[\frac{2 p(\mathrm{I}-p)}{\mathrm{I}+\frac{1}{2} p^{2}}\right]^{f} \cdot\left[\frac{p^{2}}{\mathrm{I}+\frac{1}{2} p^{2}}\right]^{g} \cdot\left[\frac{\frac{1}{2} p^{2}}{\mathrm{I}+\frac{1}{2} p^{2}}\right]^{h}
$$

which may be written:

$$
\frac{(\mathrm{I}-p)^{2 \boldsymbol{e}} \cdot(2 p)^{f} \cdot(\mathrm{I}-p)^{f} \cdot p^{2 g} \cdot \frac{1}{2}^{h} p^{2 h}}{\left(\mathrm{I}+\frac{1}{2} p^{2}\right)^{\boldsymbol{e}+f+g+h}}=\frac{(\mathrm{I}-p)^{2^{e+f}} \cdot p^{f+2 g+2 h} \cdot \frac{1}{2}^{h} \cdot 2^{f}}{\left(\mathrm{I}+\frac{1}{2} p^{2}\right)^{n}}
$$

The logarithm of the likelihood expression, denoted by $L$, is: $L=(2 e+f) \log (\mathrm{I}-p)+(\mathbf{f}+2 g+2 h) \log p-n \log \left(\mathrm{I}+\mathrm{I} \frac{1}{2} p^{2}\right)+$ const. Hence:

$$
\frac{d L}{d p}=\frac{-2 e+f}{\mathrm{I}-p}+\frac{f+2 g+2 h}{p}-\frac{n p}{\mathrm{I}+\frac{1}{2} p^{2}}=0
$$

from which $p$ is found. Its variance is given by the equation (Hogben, 1946; Mather, 1951):

$$
-\frac{\mathrm{I}}{V(p)}=\Sigma(e+f+g+h) F_{r}(p) \frac{d^{2}}{d p^{2}} \log F_{r}(p)
$$

where $F_{v}(p)$ are the expected proportions of the $e, f, g$, and $h$ classes. In the present case it assumes a somewhat complicate form, which for brevity's sake is omitted. The square root of $V(p)$ gives the standard error of the estimated $p$.

\section{RESULTS}

The data obtained from the single ears in the different years are summarised in table $\mathrm{I}$, and from the grand totals as well as from appropriate average values it is possible to gather some information about the behaviour of the balanced lethals.

In total the four classes of ears are represented, as follows:

$$
\frac{e}{4 \mathrm{IO}} \quad \frac{f}{120} \quad \frac{g}{16} \quad \frac{h}{6} \quad \frac{\text { total }}{55^{2}}
$$

Substituting in the equation ( 1 ) we obtain:

$$
-235 p^{2}-55^{2} p+82=0
$$

which gives $\hat{p}=0.140185$.

Applying formula (2) $V(p)=0.0000593229$ and, consequently, the standard error of $p$ is 0.007702 . 
Using this value of $p$ we find the expectations for $e, f, g$ and $h$ classes to be:

giving

$$
\begin{array}{ll}
\frac{(\mathrm{I}-p)^{2}}{\mathrm{I}+\frac{1}{2} p^{2}}=0.732 \mathrm{I} & \frac{2 p(\mathrm{I}-p)}{\mathrm{I}+\frac{1}{2} p^{2}}=0.2387 \\
\frac{p^{2}}{\mathrm{I}+\frac{1}{2} p^{2}}=0.0195 & \frac{\frac{1}{2} p^{2}}{\mathrm{I}+\frac{1}{2} p^{2}}=0.0097
\end{array}
$$

\begin{tabular}{|c|c|c|c|c|c|c|}
\hline Ear clas & ises & & $e$ & $f$ & $g$ & $h$ \\
\hline $\begin{array}{c}\text { Frequency : } \\
\text { Actual } \\
\text { Expected }\end{array}$ & $\dot{\cdot}$ & . & $\begin{array}{l}0.7427 \\
0.7321\end{array}$ & $\begin{array}{l}0.2174 \\
0.23^{87}\end{array}$ & $\begin{array}{l}0.0290 \\
0.0195\end{array}$ & $\begin{array}{l}0.0109 \\
0.0097\end{array}$ \\
\hline $\begin{array}{l}\text { Number of e } \\
\text { Actual } \\
\text { Expected }\end{array}$ & $\begin{array}{c}\text { ars : } \\
\dot{\cdot}\end{array}$ & . & $\begin{array}{l}4^{10} \\
404 \cdot I I\end{array}$ & $\begin{array}{l}\text { I } 20 \\
\text { 1 } 31 \cdot 77\end{array}$ & $\begin{array}{l}16 \\
10.74\end{array}$ & $\begin{array}{l}6 \\
5.37\end{array}$ \\
\hline
\end{tabular}

The last two rows give $\chi_{[2]}^{2}=4.24$ with $\mathrm{P}=0.20-0 \cdot 10$. Consequently the distribution of our ear types in the four expected classes is in good agreement with the hypothesis that $d e^{t 1}$ and $d e^{t 2}$ form a balanced lethal system in which the per cent. of recombination between the two factors for defective endosperm is $14^{\circ} \mathrm{OI} \pm \mathrm{O}^{\circ} 77$ per cent.

Using this recombination value for calculating the per cent. of defectives expected from the coupling phase $D e^{t 1} D e^{t 2} / d e^{t 1} d e^{t 2}$, a value of about 32 per cent. is found. This is somewhat less than that shown in table I $(34.49$ per cent.) for the correspondent $g$-class. This difference, though not great, is to be expected, since our method of classification obviously tended to widen the discrepancy among the groups. Undoubtedly at least some of the greatest deviations would be due to sampling variation while, on the other hand, ears would sometimes be misclassified because they presented a kernel ratio not significantly different from that expected in a genotype other than their own.

\section{DISCUSSION}

The existence of factors affecting seed characters on chromosome 4 of maize, and whose defective (amorph, hypomorph, etc.) alleles may impair a normal development, has often been observed partly because of a possible specific functional control of such genetic material on seed growth (Mangelsdorf, personal communication; Bianchi, Bellini, Contin, Ottaviano, 196r), and partly because of the fact that the gene $s u_{1}$, which marks chromosome 4 , is readily followed and hence often used by maize geneticists (Mangelsdorf, 1926; Bianchi, 1957). Consequently the building of balanced lethal systems in this chromosome should not be difficult, and, in fact, little difficulty 
was encountered, once, of course it was appreciated that in dealing with lethals, crosses have to be made among heterozygotes, with the consequence that several appropriate crossing operations must be performed in order to obtain the desired combination. In maize, however, this is not a troublesome requirement, since cross and selfpollinations may be carried out on the same ear, with the possibility

\section{TABLE I}

Total and average values of defective seeds in ears harvested from self-pollinated plants grown from normal seeds of ears showing about 50 per cent. of defectives (1955-60 crops)

\begin{tabular}{|c|c|c|c|c|c|c|c|}
\hline \multirow{2}{*}{\multicolumn{3}{|c|}{$\begin{array}{l}\text { Culture and } \\
\text { ear class }\end{array}$}} & & \multirow{2}{*}{ No. of ears } & \multicolumn{2}{|c|}{ No. of seeds } & \multirow{2}{*}{$\begin{array}{l}\text { Percentage of } \\
\text { defectives }\end{array}$} \\
\hline & & & & & defective & total & \\
\hline \multicolumn{8}{|l|}{ e-class } \\
\hline I 955 & & . & . & I 3 & $I, 570$ & $3,44^{I}$ & $45 \cdot 63$ \\
\hline I $95^{6}$ & . & . & . & 23 & $\ldots$ & $\cdots$ & $\cdots$ \\
\hline I 957 & . & . & . & 4 & $25^{6}$ & 454 & $5^{6 \cdot 39}$ \\
\hline $\begin{array}{l}195^{8} \\
\text { I } 959\end{array}$ & . & : & $\dot{.}$ & $\begin{array}{r}7 \\
19\end{array}$ & $\ddot{2,369}$ & $\dddot{4.912}$ & $4 \ddot{8 \cdot 23}$ \\
\hline 1960 & . & . & . & 344 & $53,66 \mathrm{I}$ & I 07,463 & $49 \cdot 93$ \\
\hline \multicolumn{8}{|l|}{$f$-class } \\
\hline I955 & . & . & . & 3 & 80 & $34^{8}$ & $22 \cdot 99$ \\
\hline $\begin{array}{l}1956 \\
\end{array}$ & & $\cdot$ & - & 9 & $\cdots$ & $\cdots$ & $\cdots$ \\
\hline $\begin{array}{l}195^{8} \\
1959\end{array}$ & & . & : & $\begin{array}{l}3 \\
8\end{array}$ & ${ }_{566}^{66}$ & $\dddot{2,262}$ & $25 \cdot 02$ \\
\hline 1960 & & . & . & 97 & 7,350 & 30,656 & $23 \cdot 98$ \\
\hline \multicolumn{8}{|l|}{$g$-class } \\
\hline 1955 & . & . & . & I & II 2 & 374 & $29 \cdot 95$ \\
\hline I 959 & . & . & . & I & $7 I$ & 193 & $3^{6} \cdot 79$ \\
\hline 1960 & & . & - & I4 & 1,428 & 4,104 & $34 \cdot 79$ \\
\hline \multicolumn{8}{|l|}{$h$-class } \\
\hline 1955 & & 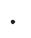 & . & I & $\ldots$ & $\cdots$ & $\ldots$ \\
\hline 1960 & & - & - & 5 & 12 & 1,546 & 0.78 \\
\hline \multicolumn{8}{|c|}{$\begin{array}{l}\text { Grand totals and general } \\
\text { averages for: }\end{array}$} \\
\hline $\begin{array}{l}e \text {-class } \\
f \text {-class }\end{array}$ & & · & $\cdot$ & 410 & 57,856 & II 6,270 & $49 \cdot 76$ \\
\hline $\begin{array}{l}f \text {-class } \\
g \text {-class }\end{array}$ & & . & - & $\begin{array}{r}120 \\
16\end{array}$ & 7,996 & 33,266 & $24 \cdot 04$ \\
\hline $\begin{array}{l}g \text {-class } \\
h \text {-class }\end{array}$ & & 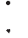 & & 6 & $\begin{array}{r}1,611 \\
12\end{array}$ & $\begin{array}{l}4,671 \\
\mathrm{I}, 546\end{array}$ & $\begin{array}{r}34 \cdot 49 \\
0 \cdot 78\end{array}$ \\
\hline
\end{tabular}

of distinguishing on it crossed and selfed kernels by using convenient endosperm markers.

In the present case the balanced lethal system, obtained in this way by Dr P. C. Mangelsdorf, is liable to break down, since there is about i 4 per cent. of recombination between the two defective factors. Even so the system can be useful in studies of heterotic phenomena, since a sizeable region of the chromosome can be kept in heterozygous condition fairly easily. The fact that the $\chi^{2}$ calculated above is not 
significant suggests also that the four different classes of zygotes $D e^{t 1} d e^{t 2} / d e^{t 1} D e^{t 2} ; D e^{t 1} D e^{t 2} / d e^{t 1} D e^{t 2}$ plus $D e^{t 1} D e^{t 2} / D e^{t 1} d e^{t 2}, D e^{t 1} D e^{t 2} /$ $d e^{t 1} d e^{t 2}$ and $D e^{t 1} D e^{t 2} / D e^{t 1} D e^{t 2}$ very likely have the same viability. This may mean that, under our experimental condition and with the present genetical background this region of chromosome 4 possesses no detectable heterotic effects, which agrees with the view that in maize, as well as in other species, such as the tomato, heterosis is due to simple dominance (Powers, 1952; Burdick, 1954; Sprague, Russell and Penny, I959).

Although a certain arbitrary element had to be introduced into the classification of the experimental material, the agreement between observations and expectations suggests that $d e^{t_{1}}$ and $d e^{t_{2}}$ may be considered as constituting a simple example of the classical balanced lethal systems.

\section{SUMMARY}

A balanced lethal system in maize is described. Both lethals are defective endosperm factors. They are placed on chromosome 4 and show a per cent. recombination of $14.018 \pm 0.770$ per cent.

Acknowledgments.-This work has been made possible by the financial support of The Rockefeller Foundation, New York, which is gratefully acknowledged. Thanks are also due to Dr P. C. Mangelsdorf, Harvard University, who provided the original material. The critical reading by Professor K. Mather, University of Birmingham is also gratefully acknowledged.

\section{REFERENCES}

BIANCHI, A., AND MANGELSDORF, P. C. 1955. Studies of defective seeds originating in teosinte-maize derivatives. Maize Genet. Coop. News Letter, 29, 24-25.

BIANchi, A. 1957. Defective caryopsis factors from maize-teosinte derivatives. I. Origin, description and segregation. Genetica agraria, 7, I-38.

BIANCHI, A. 1959. Fattori genetici determinanti cariossidi difettose in discendenti di incroci tra mais e teosinte. II. Curve di variabilità dei pesi (Convegno di Genetica, 1957). La Ricerca scientifica (Suppl.), 29, 5 I-69.

bianchi, A., Bellini, G., Contin m. AND ottaviano, E. I961. Non-disjunction in presence of interchanges involving B-type chromosomes in maize and some phenotypical consequences of meaning in maize breeding. Z.f. Vererb.-lehre, 92: 213-232.

BURDICK, A. B. 1954. Genetics of heterosis for earliness in the tomato. Genetics, $39,488-505$.

HogBen, L. 1946. An Introduction to Mathematical Genetics. Norton and Co. New York.

MATHER, K. I95I. The Measurement of Linkage in Heredity. Methuen \& Co. Ltd, London (2nd edn.).

MANGELSDORF, P. C. 1926. The genetics and morphology of some endosperm characters in maize. Conn. Agr. Exp. Sta. Bull., 279, 509-6r4.

PHIPPS, I. F. 1929. Inheritance and linkage relations of virescent seedlings in maize. Cornell Univ. Agric. Exper. St. Me., 125, 1-63.

POWERs, L. 1952. Gene recombination and heterosis. In Heterosis (J. W. Gowen ed.), Ch. 19, Iowa State College Press, Ames, Iowa.

SPRAGUE, G. F., RUSSELL, W.A., AND PENNY, L. H. 1959. Further studies on convergent improvement in corn. Genetics, 44, 341-346. 